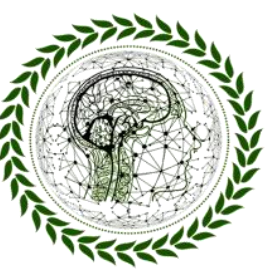

PhI Scientific Review

ISSN 2676 - 0444

Submetido em: 04/12/2021 | Aceito em: 07/12/2021 | Publicado em: 16/12/2021 | Artigo

\title{
RELAÇÃO ENTRE CONSUMO E FELICIDADE: UMA REFLEXÃO ACERCA DESSES CONCEITOS NA SOCIEDADE CONTEMPORÂNEA.
}

Rodrigo Alberto Peixoto Rodrigues de Souza ${ }^{1}$

Maria Aparecida de Souza²

Resumo: A cultura de consumo, tão imbricada em todos os aspectos da vida cotidiana, influencia diretamente o modo de (re)significar valores, perspectivas e projetos, incluindo a noção do que seja a felicidade. Nesse sentido, o consumo pode mascarar frustrações, configurar o refúgio e a autoindulgência decorrentes da vida atribulada e da falta de tempo para prazeres simples que poderiam ser desfrutados com familiares e amigos. Objetivo: Analisar a relação entre consumo e felicidade, promovendo uma discussão literária acerca de tais aspectos na sociedade contemporânea. Método: Realiza-se uma pesquisa bibliográfica, com abordagem qualitativa e interpretativa, a fim de identificar fatores determinantes que demonstrem alguma relação com o fenômeno estudado. Considerações finais: O consumo desencadeia várias sensações (satisfação pessoal, reforço de identidade social, contentamento e bemestar, mas a associação entre felicidade e consumo constitui um pensamento equivocado, pois o ato de adquirir algo não abrange fatores cognitivos importantes, como amor, carinho, saúde mental e física, entre outros tantos requisitos necessários para se obter a felicidade.

Palavras-chave: Consumo; Consumismo; Felicidade; Satisfação pessoal.

\footnotetext{
${ }^{1}$ https://orcid.org/0000-0001-5844-1931
}

${ }^{2}$ https://orcid.org/0000-0001-6860-110X

http://www.revistaphd.periodikos.com.br

V. 01, No 07, dezembro de 2021

DOI: 10.53497/phdsr1n7-004

Todos os direitos reservados $(\mathrm{C}$ 


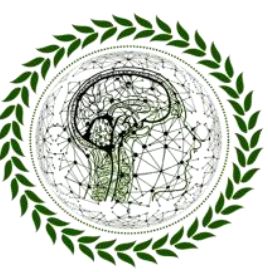

PhD Scientific Review

ISSN 2676 - 0444

\title{
RELATIONSHIP BETWEEN CONSUMPTION AND HAPPINESS: REFLECTION ON THESE CONCEPTS IN CONTEMPORARY SOCIETY
}

\begin{abstract}
Consumer culture, so imbricated in all aspects of daily life, directly influences the way of (re)signifying values, perspectives and projects, including the notion of what happiness is. In this sense, consumption can mask frustrations, configure refuge and self-indulgence resulting from a busy life and lack of time for simple pleasures that could be enjoyed with family and friends. Objective: To analyze the relationship between consumption and happiness, promoting a literary discussion about such aspects in contemporary society. Method: A bibliographical research is carried out, with a qualitative and interpretive approach, in order to identify determining factors that demonstrate some relationship with the phenomenon studied. Final considerations: Consumption triggers several sensations (personal satisfaction, reinforcement of social identity, contentment and well-being, but the association between happiness and consumption is a mistaken thought, as the act of acquiring something does not cover important cognitive factors, such as love, affection, mental and physical health, among many other necessary requirements to obtain happiness.
\end{abstract}

Keywords: Consumption; Consumerism; Happiness; Personal satisfaction.

\section{INTRODUÇÃO}

O cenário de consumo atual exerce influência no ser, no fazer, no saber e na cultura, mediante a multiplicidade de mercados, a alta exigência dos consumidores em relação a serviços e produtos, o desenvolvimento tecnológico acelerado, o advento de novas mídias, a busca pela felicidade e pela qualidade de vida, entre outras perspectivas/arrolamentos da vida cotidiana (CARVALHO CS, 2010).

Segundo Silva RB e Carvalhaes FF (2016), o termo "sociedade de consumo" está diretamente associado ao nascimento da sociedade moderna que possui, como um de seus princípios fundamentais, o materialismo. Esse consumo advém da necessidade de atenção e do interesse provocados por anúncios publicitários que incentivam as compras em geral. Nesse

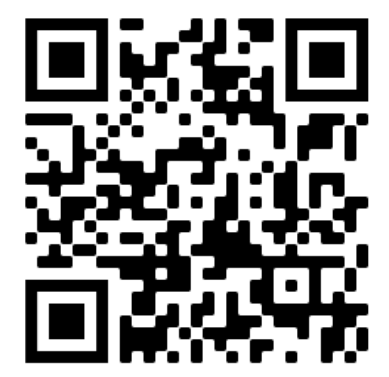

http://www.revistaphd.periodikos.com.br

V. 01, No 07, dezembro de 2021

DOI: $10.53497 /$ phdsr1n7-004

Todos os direitos reservados ( 


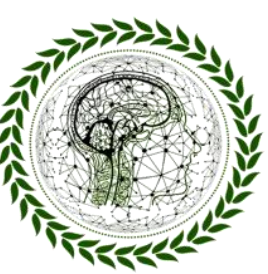

PhD Scientific Review

ISSN 2676 - 0444

cenário, nota-se uma busca incessante pela satisfação e felicidade, que poderiam ser alcançados através desse consumo (CAMPBELL C, 2006).

Como problematização dos efeitos da compra na sociedade, busca-se evidenciar a aquisição consumista como modo de vida exaltado e central da sociedade, edificada em uma promessa decorrente do sentimento de felicidade. Santos TC (2012) acredita que o materialismo interfere no desenvolvimento de uma construção social e cultural, sendo atribuído à necessidade por produtos e serviços de uso diário, assumindo relevante importância na vida da sociedade, e nas relações intra e interpessoais.

Diante do breve exposto, discute-se a relação entre o consumo e a noção de felicidade no contexto da sociedade contemporânea. Como percurso metodológico, realiza-se uma pesquisa bibliográfica, a fim de identificar fatores determinantes que possuem alguma relação com o fenômeno estudado (GIL AC, 2008), baseando-se em livros, revistas, artigos, dissertações e sites oficiais publicados nos últimos 15 anos.

Nesse sentido, acredita-se que o consumo influencia no modo de pensar, de agir e até de perceber o mundo, mas a promessa de felicidade pode ser uma ilusão e gerar sentimentos negativos, como frustação, utopia de segurança etc. Essas considerações são verificadas na literatura pesquisada sobre o assunto e discutida a seguir.

\section{REFERENCIAL TEÓRICO}

\subsection{SOCIEDADE CONTEMPORÂNEA}

A sociedade moderna usufrui da era tecnológica, midiática e globalizada, e a culturamundo é composta pela internet (comunicação), pela rapidez dos transportes, e pelas diversas plataformas que agem disseminando informações e interferindo até mesmo na identidade e padrões de vida do sujeito (SILVA RB; CARVALHAES FF, 2016).

http://www.revistaphd.periodikos.com.br

V. 01, $\mathrm{N}^{\circ} 07$, dezembro de 2021

DOI: 10.53497/phdsr1n7-004

Todos os direitos reservados $\odot$ 


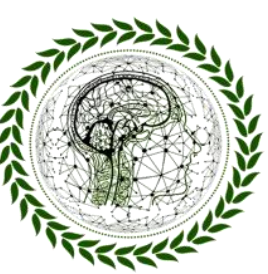

PhD Scientific Review

ISSN 2676 - 0444

De acordo com Castells M (2016), a rede interativa juntou textos, imagens e sons em uma mesma plataforma, no intuito de estimular compartilhamentos, e, ao mesmo tempo, imediatismos com produtos e serviços anunciados. O mesmo autor entende que a sociedade em rede oportuniza diversas questões que atingem a sociedade.

Por sua vez, Santos TC (2012) explica que, em tempos em que tudo é passível de ser trocado, descartado, inutilizado, desperdiçado, práticas e sentimentos se mostram cambiantes, provisórios, limitados, devido à fragilidade/instabilidade das relações estabelecidas com o consumo.

Soares JS e Souza MCS (2018) sugerem que o desenvolvimento e a propagação de bens de consumo são disponibilizados com a intenção de despertar o desejo e a necessidade e, com eles, estabelecer uma relação de consumo e prazer. Do mesmo modo, Carvalho CS (2010, p. 13) afirma que:

(...) o estabelecimento da cultura de consumo imersa em uma Sociedade de Consumo teve influência direta em vários âmbitos da vida cotidiana. É importante ressaltar que a este processo corresponde uma industrialização da cultura e a mercantilização da vida cotidiana e que a cultura de consumo é também a cultura das mídias. Assim, as mídias fazem o papel de combustível desta cultura de consumo operando o que Bourdieu (2000) destaca como a pedagogia do consumo. A energia gerada sob a forma de uma constante formulação e reformulação de universos simbólicos é levada através da programação dos meios de comunicação, seja na forma de produto cultural seja em sua forma mais explicita: a Publicidade.

Moura RA (2018) confirma que o mercado de consumo se faz presente e induz à necessidade de ter, possuir, obter, impondo, cotidianamente, novos produtos divulgados pelas várias mídias que vendem a necessidade de obter benefícios, diferenciais e promessas. Nesse sentido, por causa dessa infinidade de produtos e serviços oferecidos pelo mercado, e que são constantemente substituídos, ou se tornam ultrapassados, permanece-se em uma constante busca por conforto, felicidade, praticidade e outros sentimentos que o mercado desperta.

Para Lipovetsky G e Hervé J (2012, p. 18), trata-se do momento “da comercialização

http://www.revistaphd.periodikos.com.br

V. 01, No 07, dezembro de 2021

DOI: $10.53497 /$ phdsr1n7-004

Todos os direitos reservados@ 


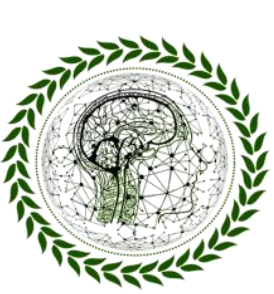

PhI Scientific Review

ISSN 2676 - 0444

quase integral de tudo - não apenas de objetos, como também da cultura, da arte, do tempo, da comunicação, da procriação, da vida e da morte, ou seja, uma cultura hiperconsumista”. Assim, percebe-se que a sociedade de consumidores representa o tipo de sociedade que promove, encoraja ou reforça a escolha de um estilo de vida enquanto estratégia existencial consumista.

Nos dizeres de Costa MV (2009), o mundo é caracterizado pela descartabilidade, pela velocidade, pela volatilidade, pela compressão espaço tempo, pela excessiva visibilidade, pela ambivalência, pela fugacidade, pela instantaneidade, pela obsolescência, pela efemeridade, pelo individualismo, pela busca de pertencimento, pela incompletude, entre tantas outras dimensões.

\subsection{ESTADO DE FELICIDADE}

A palavra "felicidade" vem do latim felicitate, que significa estado de quem é feliz; ventura; bem-estar, contentamento; bom resultado, bom êxito (MICHAELIS, 1998). Considera-se que qualquer pessoa pode formular uma resposta sobre o conceito de felicidade, mas cada resposta obtida será baseada em necessidades e sentimentos específicos (particulares). Portanto, coisas ou situações diferentes podem definir ou exprimir o sentimento de felicidade, sendo que o que representa felicidade para um indivíduo, pode não representar para outro. Conforme Carvalho CS (2010), trata-se de um tema subjetivo e de difícil mensuração. Ainda assim, verifica-se que o termo felicidade possui o senso comum de significar o estado de ser feliz; estado de uma consciência plena de satisfação, de contentamento e de bem-estar (SILVA RB; CARVALHAES FF, 2016).

Carvalho CS (2010, p. 31) define felicidade como:

[...] um estado de plena satisfação de nossos desejos, ou seja, um momento a partir do qual tudo que se buscava realizou-se e foi alcançado. Corresponderia a um estado de contentamento perfeito em que cada desejo saciado resulta em um acumulo de satisfação que culminará em um período de integralização deste contentamento que passa então a ser permanente. Significa também que não há mais nada o que desejar já 


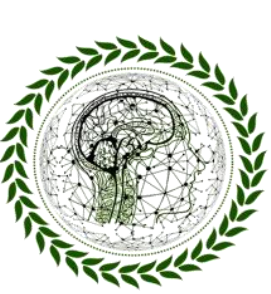

PhI Scientific Review

ISSN 2676 - 0444

que o desejo se esvai na medida da sua realização, morre no êxtase do prazer.

Em contrapartida, Moura RA (2018, s. p.) postula que a felicidade:

[...] é momentânea, pouco duradoura. (...) a felicidade constitui a referência absoluta da sociedade de consumo, revelando-se como o equivalente autêntico da salvação. Tão logo seus desejos sejam satisfeitos, o ser humano deixará de ser feliz, até surgirem novos desejos. Os momentos que alternam felicidades e infelicidades provocarão altos e baixos nas vidas das pessoas, causando, muitas vezes, patologias de difíceis soluções, como estresse e depressão.

Nessa perspectiva, salienta-se que o ser humano necessita de um fundamento para obter felicidade e prazer, pois tais estados não podem ser intencionados. Então, pensar em satisfazer um desejo, consumir um produto e ter isso como felicidade seria um erro, pois surgiriam novos desejos que deixariam as pessoas infelizes até a realização desses (MOURA RA, 2018).

Contudo, sabe-se que o mercado e o marketing, em seus anúncios, colocam a felicidade à venda na prateleira do mercado, da farmácia, e, ou nas araras de lojas, na forma de objeto, como bem destaca Lipovetsky G (2007).

Silva RB e Carvalhaes FF (2016) corroboram que, na sociedade atual, o estado de felicidade está diretamente associado ao consumo. Quando algo é consumido, satisfazem-se os desejos, como se o produto adquirido fosse um remédio da felicidade comprado em uma farmácia.

Carvalho CS (2010) pondera que é um erro limitar a sensação de felicidade como um estado de realização plena, de satisfação imediata e simultânea de todos os desejos, pois o homem necessita de novos desejos para se manter ativo e fugir do tédio.

Isso posto, há de se questionar se a busca da felicidade pode se limitar à aquisição de algo. Nesse caso, o consumo, que pode ser compreendido como o ato ou o efeito de consumir, traz a sensação de felicidade, causando o sentimento de realização e de conquista. Assim, sem perceber, as pessoas se transformam em escravos do consumismo material (MOWEN J; MINOR M, 2008;

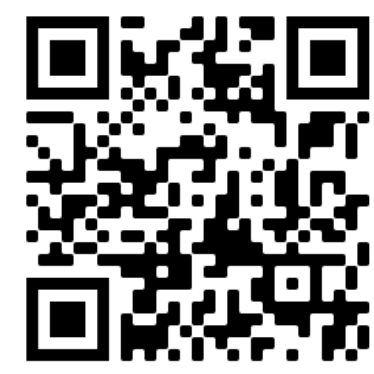

http://www.revistaphd.periodikos.com.br

V. 01, No 07, dezembro de 2021

DOI: 10.53497/phdsr1n7-004

Todos os direitos reservados@ 


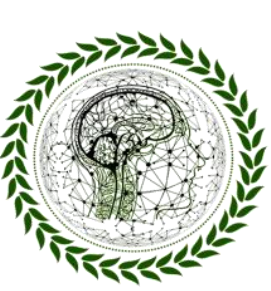

PhI Scientific Review

ISSN 2676 - 0444

COSTA MV, 2009).

Lima LC (2011) explica que comprar algo para buscar a satisfação é normal, contudo, a tendência é a perpetuação do ciclo, pois sempre existirão frustrações e, assim, o que era normal pode se tornar um transtorno, chamado pelos especialistas de "oniomania", um transtorno para compras desenfreadas. Vale pontuar que esse consumo não é exclusivo das classes mais altas, mas essas servem-se deste meio para exporem socialmente sua riqueza e ociosidade, sinais exteriores de riqueza (MOWEN J; MINOR M, 2008).

\subsection{DIFERENÇA ENTRE CONSUMO E CONSUMISMO}

Atualmente, tudo o que é consumido tem um apelo cultural e mercadológico, o que influencia significativamente no comportamento do consumo humano. Nesse sentido, percebe-se o consumo como um estilo de vida em uma sociedade cada vez mais materialista, cujo princípio básico é a sedução - estabelecida pelas mídias nas relações de consumo. (LIPOVETSKY G, 2007).

Conforme conceituação do Dicionário Michaelis, consumismo é "ato, efeito, fato ou prática de consumir (comprar em demasia)" e "consumo ilimitado de bens duráveis, especialmente artigos supérfluos". Em outras palavras, consumismo pode ser definido como "uma compulsão para consumir", enquanto consumo pode ser entendido como "as aquisições racionais, controladas e seletivas baseadas em fatores sociais e ambientais e no respeito pelas gerações futuras” (MICHAELIS, 2020). Para Cortez ATC e Ortigoza SAG (2009, p. 35), "consumismo é o ato de comprar produtos ou serviços, muitas vezes, sem consciência".

Sob esse viés, observa-se que estabelecer limites entre consumo e consumismo é extremamente complicado, já que a ideia de consumo e de consumismo varia de forma individual, a depender de sua mentalidade, educação e classe social (CAMPBELL C, 2006). Lipovetsky G (2007) atesta que analisar a relação entre consumo e consumismo é tarefa árdua,

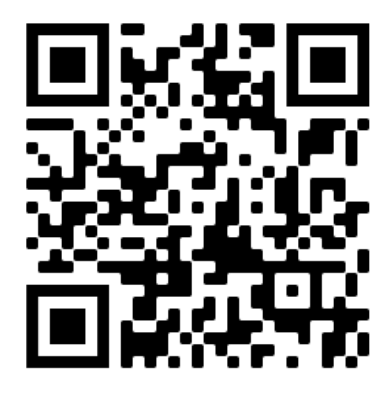

http://www.revistaphd.periodikos.com.br

V. 01, No 07 , dezembro de 2021

DOI: 10.53497/phdsr1n7-004

Todos os direitos reservados ( 


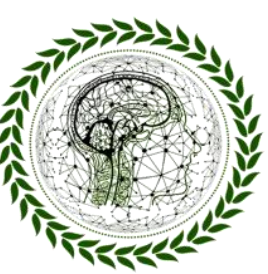

PhD Scientific Review

ISSN 2676 - 0444

não raro sem expectativa de uma resposta que possa ser considerada conclusiva. Há uma linha tênue que separa ambos, delineada pela consciência do comprador.

Delineia, pois, Cacemiro W (2016), ainda nesse sentido, que a aquisição está relacionada a compras realizadas por necessidade, como itens alimentícios, medicamentos etc. Já o consumismo seria associado à compra de artigos não essenciais à vida e à saúde (ou seja, que não fariam falta se não fossem adquiridos).

Além disso, é possível diferenciar consumismo de consumo por meio da análise da quantidade - não há nada de errado ao consumir algo, mas dependendo da frequência desse consumo, se a todo instante você sente necessidade e adquire novos produtos, isso é considerado consumismo (SOARES JS; SOUZA MCS, 2018).

Para mostrar que o consumo é absolutamente dissociado da satisfação, Baudrillard J (2009) sublinha o caráter de dever que o gozo assume na sociedade. O homem-consumidor busca desse um corpo perfeito, ou cosméticos que prometem a juventude eterna, a roupas e viagens; tudo isso feito para, enquanto compra, vender a ideia de ser bem-sucedido, de adquirir felicidade.

Nesse contexto, é válido apresentar o conceito de marketing, que pode ser entendido como a entrega de valor para o cliente, incluindo o preço a se pagar pelo produto/serviço, além dos benefícios que esse produto ou serviço proporciona a quem compra. Assim, o marketing abrange as necessidades e os desejos que determinados produtos propiciam à vida do sujeito (STECCA FLP, ÁVILA LV, 2015).

Cacemiro W (2016) complementa que o marketing vende mais do que produtos, isto é, a compra deixa de ser somente um ato aquisitivo de bens por si próprios, mas, em um sentido metafórico, aquilo que se compra assume um significado simbólico, como a falsa (ou no mínimo volátil) sensação de felicidade.

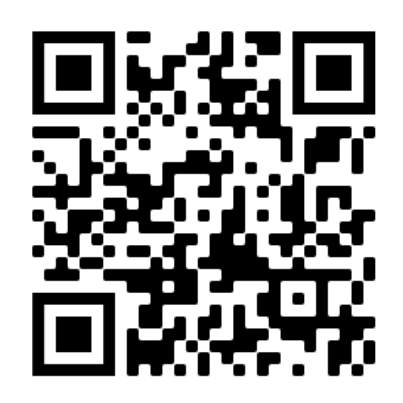

http://www.revistaphd.periodikos.com.br

V. 01, No 07, dezembro de 2021

DOI: $10.53497 /$ phdsr1n7-004

Todos os direitos reservados (C) 


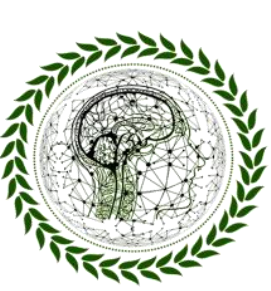

PhI Scientific Review

ISSN 2676 - 0444

\section{CONSIDERAÇÕES FINAIS}

No presente estudo, buscou-se analisar a relação entre consumo e felicidade. A literatura permite afirmar que o consumo desencadeia várias sensações, tais como satisfação pessoal, identidade social, contentamento e bem-estar. Contudo, o estado de felicidade não depende somente de consumo para acontecer, e a associação entre felicidade e consumo constitui um pensamento equivocado, pois o ato de adquirir algo não abrange fatores cognitivos importantes, como amor, carinho, saúde mental e física, entre outros tantos requisitos necessários para se obter ou alcançar a felicidade.

\section{REFERÊNCIAS}

BAUDRILLARD, J. Sociedade de Consumo. Lisboa: Edições 70, 2009.

CACEMIRO, W. Consumo x consumismo: uma análise crítica sobre o tema. Jus.com.br. 4-022016. Disponível em: https://jus.com.br/artigos/48047/consumo-x-consumismo-uma-analisecritica-sobre-o-tema. <Acesso em 08 de jun. 2021>.

CAMPBELL, C. Eu compro, logo sei que existo: as bases metafísicas do consumo moderno. In BARBOSA, L; CAMPBELL, C (Org.). Cultura, consumo e identidade. Rio de Janeiro: Ed. FGV, 2006. p. 47-64.

CARVALHO, CS. O consumo e a representação da felicidade em 40 anos de propaganda brasileira. Dissertação apresentada ao Curso de Mestrado em Comunicação, da Faculdade de Comunicação e Biblioteconomia. Universidade Federal de Goiás, Goiânia, 2010. 167 f.

CASTELLS, M. O poder da comunicação. São Paulo: Paz e Terra, 2016.

CORTEZ, ATC; ORTIGOZA, SAG. Da produção ao consumo: impactos socioambientais no

http://www.revistaphd.periodikos.com.br V. 01, N 07, dezembro de 2021 DOI: $10.53497 /$ phdsr1n7-004 Todos os direitos reservados $(\mathrm{C}$ 


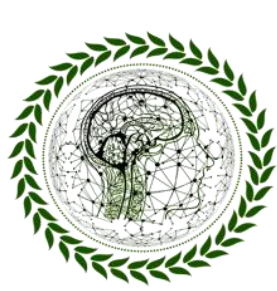

PhI Scientific Review

ISSN 2676 - 1444

espaço urbano [online]. São Paulo: Editora UNESP; Cultura Acadêmica, 2009.

COSTA, MV. Educar-se na sociedade de consumidores. In Marisa Vorraber Costa (Org.). A educação na cultura da mídia e do consumo. 2009, Rio de Janeiro: Lamparina, pp. 35-37.

GIL, AC. Como elaborar projetos de pesquisa. 5 ed. São Paulo: Atlas, 2008.

LIMA, LC. Teoria da Cultura de Massa. Rio de Janeiro. Paz e Terra, 2011.

LIPOVETSKY, G. A felicidade paradoxal: ensaio sobre a sociedade de hiperconsumo. São Paulo: Companhia das Letras, 2007.

LIPOVETSKY, G; HERVÉ, J. A globalização ocidental: Controvérsia sobre a cultura planetária. São Paulo: Manole, 2012.

MICHAELIS. Moderno dicionário da língua portuguesa. São Paulo: Melhoramentos, 2020. Dicionário Michaelis. 2259 p.

MOURA, RA. Consumo ou consumismo: uma necessidade humana? Rev. Fac. Direito São Bernardo do Campo, 2018, (24)1, 14p.

MOWEN, J.; MINOR, M. Comportamento do Consumidor. 3 ed. São Paulo: Pearson, 2008.

SANTOS, TC. Comunicação e as transformações na cultura do consumo. Revista FAMECOS, 2012. (19):208-224.

STECCA, FLP; ÁVILA, LV. Gestão de marketing. Santa Maria: Universidade Federal de Santa Maria, Colégio Politécnico, 2015. 86 p.

SILVA, RB; CARVALHAES, FF. Consumo e felicidade na contemporaneidade. Revista Espaço Acadêmico, dez, 2016, (16)187. Disponível em: 


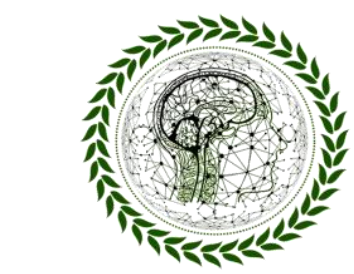

PhI Scientific Review

ISSN 2676 - 0444

https://periodicos.uem.br/ojs/index.php/EspacoAcademico/article/view/34331. Acesso em jun. 2021.

SOARES, JS; SOUZA, MCS. Sociedade de consumo e o consumismo: implicações existenciais na dimensão da sustentabilidade. 2018. Disponível em: https://periodicos.unipe.br/index.php/direitoedesenvolvimento/article/view/815/590. Acesso em jun. 2021. 